\title{
Tuberculosis infection and epidemiological characteristics in Haidian District, Beijing, 2005-2018
}

\author{
Fan $\mathrm{Wu}^{1,2+}$, Caiyun Lai ${ }^{1 \dagger}$, Yan Wang ${ }^{1 \dagger}$, Gaoqiang Zhang ${ }^{1}$, Yueqi $\mathrm{Li}^{1}$, Susu Yu', Xinyue Peng ${ }^{1}$, Jiani Yang ${ }^{1}$,
} Zhisheng Wei ${ }^{2^{*}}$ and Wenjuan Zhang ${ }^{1 *}$ (1)

\begin{abstract}
Background: This study was aimed to investigate the epidemiological characteristic of pulmonary tuberculosis (PTB) in Haidian District, Beijing from 2005 to 2018 and to provide suggestions for controlling tuberculosis (TB) development.

Methods: Epidemiological data about TB were obtained by the Infectious Disease Reporting System at different levels of medical institutions in Haidian District of Beijing from 2005 to 2018. The epidemiological methods combined with $x^{2}$ test were used to analyze the distribution of TB in population, time, region and TB diagnosis.

Results: In total, 14,449 cases of TB patients were reported in Haidian District from 2005 to 2018 and the average annual morbidity was 31.67/10,000. Of the total cases, housework and unemployed people $(20.73 \% ; 2996 / 14,449)$ accounted for the highest proportion of occupational distribution, followed by students, accounting for 17.18\% (2482/ 14,449). 2433 patients with the age of 65 years and over accounting for $16.83 \%(2433 / 14,449)$; Laboratory confirmed diagnosis of TB was $26.60 \%$ and the diagnostic delays accounted for $54.96 \%$.

Conclusions: From 2005 to 2018, TB incidence was falling gradually in Haidian District. However, particular attention should be paid to the elderly and student groups, and the policy publicity and education should be strengthened to reduce the diagnosis delay of TB.
\end{abstract}

Keywords: Tuberculosis, Epidemiology, Etiological diagnosis, Beijing

\section{Background}

Tuberculosis (TB), an ancient infectious disease caused by the bacillus Mycobacterium tuberculosis, have affected humans for thousands of years. It is the ninth leading cause of death worldwide and the leading cause of death by a single infectious agent, ranking above HIV/AIDS. Millions of people are infected with TB each year according to the World Health Organization (WHO) [1].

\footnotetext{
*Correspondence: sjqfangbaoke@163.com; zwj2080@126.com

${ }^{\dagger}$ Fan Wu, Caiyun Lai and Yan Wang contributed equally to this work. 2 Department of preventive health care, Four Seasons Hospital, Haidian District, Beijing 100097, People's Republic of China

${ }^{1}$ Department of Public Health and Preventive Medicine, School of Medicine, Jinan University, Guangzhou, Guangdong 510632, People's Republic of China
}

TB may spread from ill person to healthy person through the air via coughs, sneezes and spit.

It was estimated that 10 million people fell ill with $\mathrm{TB}$ in 2017 in the world. China was one of the 30 countries with a heavy burden of $\mathrm{TB}$, accounting for $9 \%$ of TB patients, with 63 deaths in every 100,000 people. Mozambique, Philippines and South Africa are the three countries with the highest burden of $\mathrm{TB}$, with more than 500 cases of every 100,000 people. Specific targets for 2030 set in the End TB Strategy would reduce 90\% in the absolute number of TB deaths and $80 \%$ in TB incidence (new cases per 100,000 people per year), compared with those in 2015 separately [1].

(c) The Author(s). 2020 Open Access This article is licensed under a Creative Commons Attribution 4.0 International License, which permits use, sharing, adaptation, distribution and reproduction in any medium or format, as long as you give appropriate credit to the original author(s) and the source, provide a link to the Creative Commons licence, and indicate if changes were made. The images or other third party material in this article are included in the article's Creative Commons licence, unless indicated otherwise in a credit line to the material. If material is not included in the article's Creative Commons licence and your intended use is not permitted by statutory regulation or exceeds the permitted use, you will need to obtain permission directly from the copyright holder. To view a copy of this licence, visit http://creativecommons.org/licenses/by/4.0/ The Creative Commons Public Domain Dedication waiver (http://creativecommons.org/publicdomain/zero/1.0/) applies to the data made available in this article, unless otherwise stated in a credit line to the data. 
In 1991, the Chinese government introduced Directly Observed Treatment, Short-course (DOTS) strategy, and created the national TB control system, with TB dispensaries and medical institutions at all levels, including rural primary health service networks and urban community health service institutions [2]. Especially, after the Severe Acute Respiratory Syndrome (SARS) was brought under control in 2003, the government increased public-health funding, revised laws of infectious diseases control, implemented the world's largest internet-based disease reporting system, and started a programme to rebuild local public-health facilities in China [3].. The report of the fifth national sample survey pointed out that the prevalence of TB in eastern China in 2020 had declined compared with that in 2000 [4]. With timely diagnosis and correct drug treatment, most people with TB could be cured, but there are still many people falling ill TB every year, bring the great health and economy burdens.

The average resident population in Beijing is 21,640, 000, Haidian District is located in the west and northwest of Beijing city, with an annual resident population of 3,260,000. It has the highest GDP among sixteen districts. There are many colleges and tourists attractions, such as the famous Peking University, Tsinghua University, the Summer Palace and the Zhongguancun Science Park in China. With the prosperous economic and educational environment, it attracted a large number of immigrants and floating people from different regions of China and other countries. About 344,400 foreigners visit the Haidian District every year. As different populations are prone to gather here, the disease spread easily. Therefore, we collected the TB data of Haidian District and analyzed the epidemiological characteristics to provide the theoretical basis and data reference for its prevention and control in Beijing, China.

\section{Methods \\ Data inclusion}

The diagnosis of TB is based on etiology (including bacteriology and molecular biology), combined with clinical manifestations, chest imaging, epidemiological reasons, and other auxiliary examinations for comprehensive analysis. TB cases were based on $\geq 1$ of the following diagnostic criteria, including sputum or body fluid and tissue of smearpositive for acid-fast bacilli (AFB), culture-positive of $\mathrm{Myco-}$ bacterium tuberculosis complex, or both; or clinical appearance, radiographic appearance, or both. A patient $>2$ initial sputum smear examinations (direct smear microscopy) AFBpositive; or 1 sputum examination AFB-positive plus radiographic abnormalities, symptoms, or both consistent with active PTB was diagnosed as smear-positive PTB (SPPTB). The diagnosis of smear-negative PTB (SNPTB) case predominantly was relied on clinical symptoms (such as cough for $>2$ weeks, fever for $>2$ weeks, weight loss, hemoptysis) together with abnormal chest radiograph, the results of bacterial culture, and the response to diagnostic anti-TB treatment.

\section{Classification methods and definitions}

TB has appeared among all ages including children under 14 years old, so we divide the age into eight stages with the interval of 14 . There were 19 occupations in the information system report, among which cadres staffs refer to the employees working in public institutions; Housework are those without a formal job and the unemployed mean people who are unemployed and were reported as such by the respondents; Others refer to people holding occupations other than those listed. Workers were those patients reported to be employed for physical or technical work to earn wages. Migrant workers refer to those individuals who came from rural areas, but engaged in non-agricultural work in cities. Unknowns meant without the occupation report in detail. The delay in diagnosis was defined as more than 2 weeks from the reported onset of TB symptoms to diagnose at a hospital.

\section{Data source}

The information of TB patients came from the Chinese Tuberculosis Management Information System. The regional distribution data of Haidian District were derived from the National Bureau of Statistics, and the population data came from Beijing statistical yearbook. Data used in this study were collected from records on condition of anonymity.

\section{Statistical analysis}

Categorical variables were summarized as proportions including sex and patients type (SPPTB or SNPTB). The continuous variables (age) was summarized with mean and standard deviation (mean $\pm \mathrm{SD}$ ). The Chi-squared test was used to assess the difference in categorical variables. All analyses were performed using SPSS software (version 16.0). The criterion was $P<0.05$, based on twosided tests for statistical significance.

\section{Results}

The epidemic situation of TB cases

There were 14,449 TB cases during 2005-2018 in Haidian District, with an average annual incidence rate of $32.67 / 100,000$. The new occurrences were 14,371 $(99.46 \% ; 14,371 / 14,449)$ and the treated/recurrent cases were $78(0.54 \% ; 78 / 14,449)$ as shown in Table 1 . Meanwhile, there were 134 cases of combined pleurisy and 2 carriers of pathogens in 2005. The 5 rifampicin-resistant cases were reported in 2017 and 25 rifampicin-resistant cases in 2018 respectively. The morbidity of TB was the 
Table 1 The morbidity and case type of TB patients in Haidian District, 2005-2018

\begin{tabular}{|c|c|c|c|c|c|}
\hline \multirow[t]{2}{*}{ Year } & \multirow{2}{*}{$\begin{array}{l}\text { no. } \\
\text { patients }\end{array}$} & \multirow{2}{*}{$\begin{array}{l}\text { Morbidity } \\
(/ 100,000)\end{array}$} & \multicolumn{2}{|l|}{ Case type } & \multirow{2}{*}{$\begin{array}{l}\text { TB } \\
\text { pleurisy }\end{array}$} \\
\hline & & & New cases & treated cases or recurrence & \\
\hline 2005 & 986 & 38.13 & 983 & 3 & 27 \\
\hline 2006 & 767 & 28.54 & 754 & 13 & 19 \\
\hline 2007 & 732 & 26.01 & 723 & 9 & 7 \\
\hline 2008 & 912 & 31.13 & 891 & 21 & 9 \\
\hline 2009 & 1283 & 41.63 & 1279 & 4 & 2 \\
\hline 2010 & 1204 & 36.70 & 1200 & 4 & 6 \\
\hline 2011 & 1251 & 36.77 & 1242 & 9 & 9 \\
\hline 2012 & 1228 & 35.25 & 1224 & 4 & 3 \\
\hline 2013 & 1118 & 31.26 & 1116 & 2 & 6 \\
\hline 2014 & 1057 & 28.74 & 1055 & 2 & 6 \\
\hline 2015 & 1036 & 28.05 & 1032 & 4 & 6 \\
\hline 2016 & 965 & 26.86 & 965 & 0 & 5 \\
\hline 2017 & 1011 & 29.05 & 1010 & 1 & 13 \\
\hline 2018 & 899 & 26.77 & 897 & 2 & 16 \\
\hline Total & 14,449 & $32.67^{*}$ & 14,371 & 78 & 134 \\
\hline
\end{tabular}

*Table footnotes: The average annual morbidity

highest in 2009 with an incidence rate of up to 41.63/ 100,000 and this has begun to decrease since 2009 until a small increase in 2017. The lowest annual incidence was 26.01/100,000 in 2007.

\section{Population distribution analysis}

As summarized in Table 2, the number of TB was 1.69 times greater in males than in females from 2005 to 2018 in Haidian District. The number of males was 9083 with the annual average morbidity of $49.09 / 100,000$, while the number for females was 5366 with the annual average morbidity of $31.42 / 100,000$. There was a significant sex difference the incidence $(P<0.001)$. The average age of these patients was 39.69 years. The number of young people, aged from 15 to 24, was highest with a total of 4380 cases $(30.31 \% ; 4380 / 14,449)$, followed by those who were 25 to 34 years old with a total number of $3626(25.10 \% ; 3626 / 14,449)$. Only $0.41 \%(59 / 14,449)$ of total of TB patients were 14 years old group or less. The oldest patient was 101 year of age and the youngest one was only one day old. The significant difference was observed in each age group $(P<0.001)$. In terms of different occupations, the housework and unemployed individuals comprised 2996 cases, accounting for 20.73\% $(2996 / 14,449)$ and the students up to 2482 cases, occupying for $17.18 \%(2482 / 14,449)$.

\section{Local distribution}

TB cases occurred in 22 streets and 7 towns in Beijing Haidian District during the investigation period. The total number of cases was 11,359 in The 3843 cases were diagnosed solely as laboratory-confirmed and 2761 in towns, accounting for $78.6 \%(11,359 / 14,449)$ and $19.1 \%$ $(2761 / 14,449)$ respectively. Additionally, there were 329 persons with unknown addresses, occupying 2.3\% (329/ $14,449)$ of the total number of cases. The incidence rate was the highest in 2009 of urban population, and has been declining gradually since then. However the incidence rate of town population increased gradually from 2005 to 2009, and remained stable thereafter (Fig. 1).

\section{Etiological diagnosis}

The 3843 cases were diagnosed solely as laboratoryconfirmed cases, and 10,606 cases were determined by radiographic appearance and laboratory diagnosis as the clinical cases, accounting for $26.6 \%(3843 / 14,449)$ and $73.4 \%(10,606 / 14,449)$ of the total cases respectively, of which 134 had pleurisy. The clinical diagnosis exhibited a downward trend, while the laboratory confirmation showed an upward trend from 2005 to 2018 from Fig. 2. The highest positive rate occurred in 2018 and the number of smear positives highest in 2011. There was a total of 3849 bacteria positive cases including smear-positive, positive bacterial culture and Rifampin resistance. The bacteria negative reached 7344 cases and the average rate of sputum was $77.47 \%(11,193 / 14,449)$ (Table 3).

\section{Diagnosis time}

As illustrated in Fig. 3, the average diagnosis time was 56.41 days with the median of 18 days. The average diagnosis time was 55.72 days for smear positive. Among them, 6 cases were diagnosed in advance and the earliest 
Table 2 The patient demographics of TB in Haidian District, Beijing, 2005-2018

\begin{tabular}{|c|c|c|c|}
\hline Characteristics & $f$ & (\%) & $p$-value \\
\hline \multicolumn{4}{|l|}{ Age,(years) } \\
\hline $0-14$ & 59 & 0.41 & \\
\hline $15-24$ & 4380 & 30.31 & \\
\hline $25 \sim 34$ & 3626 & 25.10 & \\
\hline $35 \sim 44$ & 1481 & 10.25 & $<0.001$ \\
\hline $45 \sim 54$ & 1306 & 9.04 & \\
\hline $55 \sim 64$ & 1164 & 8.06 & \\
\hline $65 \sim 74$ & 976 & 6.75 & \\
\hline$\geq 75$ & 1457 & 10.08 & \\
\hline \multicolumn{4}{|l|}{ Sex } \\
\hline Female & 5366 & 37.14 & \\
\hline Male & 9083 & 62.86 & $<0.001$ \\
\hline \multicolumn{4}{|l|}{ Career } \\
\hline Housework and unemployed & 2996 & 20.73 & \\
\hline Students & 2482 & 17.18 & \\
\hline Retired staffs & 2189 & 15.15 & \\
\hline Cadre staffs & 1960 & 13.56 & \\
\hline Others & 1028 & 7.11 & \\
\hline Business servicers & 921 & 6.37 & \\
\hline Workers & 835 & 5.78 & \\
\hline Farmers & 513 & 3.55 & \\
\hline Unknown & 422 & 2.92 & \\
\hline Food and beverage industry workers & 273 & 1.89 & \\
\hline Migrant workers & 239 & 1.65 & \\
\hline Teachers & 215 & 1.49 & \\
\hline Medical staffs & 167 & 1.16 & \\
\hline Public place attendants & 163 & 1.13 & \\
\hline Scattered children & 18 & 0.12 & \\
\hline Seafarers and long distance drivers & 18 & 0.12 & \\
\hline Nurses and babysitters & 5 & 0.03 & \\
\hline Kindergarten children & 3 & 0.02 & \\
\hline Herders & 2 & 0.01 & \\
\hline Total & 14,449 & - & \\
\hline
\end{tabular}

was 1 year. The 7941 people showed a diagnosis delay between 2005 and 2018, accounting for $54.96 \%$ of the total case. Among the delayed diagnosis cases, 1591 cases were smear-positive and 5115 cases were smearnegative, with the delay rates of $20.04 \%$ (1591/7941) and $64.41 \%(5115 / 7941)$ respectively. The smear-positive diagnosis delay rate was less than the smear-negative with the statistically significant difference $(P<0.001)$.

\section{Discussion}

In this study, the TB morbidity was decreased by $29.8 \%$ (from 38.13 to 26.77 per 100,000 population) in Haidian District of Beijing from 2005 to 2018 with an average annual morbidity of $32.67 / 100,000$, closely to the total incidence of TB reported in Beijing in 2017 (32.70 per 100, 000 population) [5], but far lower than that in China in 2017 (63 per 100,000 population) [1], which was closely related with the national policies to control the incidence of TB. Since 1949, China has paid much attention to the prevention and control of TB. The Chinese government incorporated this issue into the economic and social development plan, continuously increased the investment of prevention and control funds, strengthened the construction of institutions, and constantly improved the prevention and control service system. There was an important period of improvement and innovation in TB control from 2001 to 2010. By the end of 2005, China's DOTS coverage had reached 100\% [6].

From the perspective of age distribution, most patients were young adults aged from 15 to 44 . However, the increasing attention should be placed on the old population over 75 years old. Many relapsed patients were found in the elderly population [7]. The immunity of the elderly population has generally weakened, and hence prone to infection or relapse. Additionally, some investigations showed that the BCG vaccine was more useful for younger people and less effective for the middle or seniorage people, with an average efficacy of only about $50 \%$ for those groups [8]. Considering the rapid aging of the Chinese population and high morbidity rate of TB in seniors, we should pay more attention to the potential high-risk elderly sub-populations who may contribute to the increased proportion of the actively infected people [9]. In this context, an effective vaccine control strategy should be implemented for them to reduce their TB morbidity.

The results showed that the most cases were distributed in urban areas, where a number of colleges and universities were located, As a consequence, students were found to be a high-risk group of TB. TB was easy to spread among crowed population, leading to the prevalence in campus areas. Schools are considered common places for the community-based of outbreak of TB in China, so the exposure risk in the dorm room and tuberculin test results should be taken into consideration in prevention and control $[10,11]$. Moreover, although students were screened, no surveillance, follow-up or control activities were carried out, which may result in delays in the diagnosis of TB and thus caused its wide spread [12]. Therefore, the delayed diagnosis, lacked of preventive treatment and no follow-ups were the typical contributing factors in the outbreak of school TB.

Our study found that the incidence of TB in males was higher than that in females, and the occupational distribution 


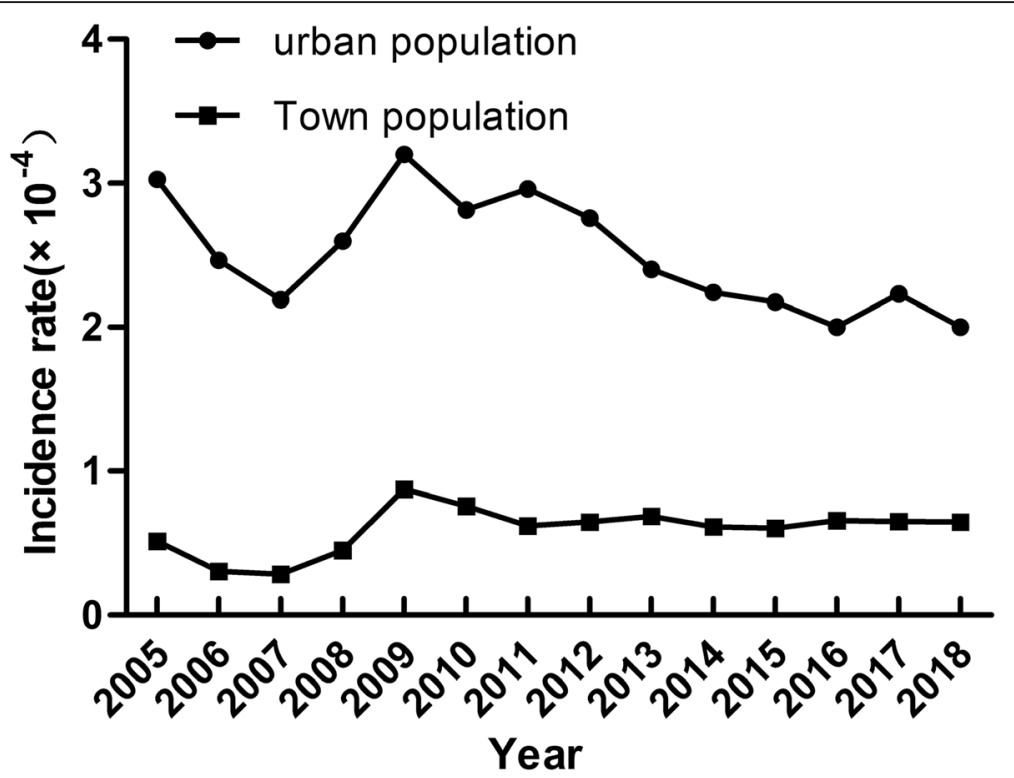

Fig. 1 Regional distribution of TB. The incidence rate of TB in two different populations, including the local urban and town populations in Haidian District of Beijing, 2005-2018

of TB was mainly due to housework and unemployment and students. These were well explained by cluster aggregation. Men may have a higher morbidity of latent TB infection and greater exposure to conditions that favor the development of the disease, such as alcoholism, smoking and precarious working conditions $[13,14]$. In the decade after the outbreak of SARS in China, TB incidence showed an increasing trend by age, especially noticeable among men [15].

From 2005 to 2018 in Haidian District, the positive rate of laboratory detection was lower than the $50 \%$ positive rate of pathogen diagnosis proposed in the 13th Five-Year National Tuberculosis Control Plan.
Meanwhile, the smear-positive diagnosis delay rate was significantly less than that of the smear-negative diagnosis. Therefore, the laboratory testing level should be strengthened, and conventional smear culture should be combined with genetic testing to improve the detection rate of pathogens in Haidian District in the future. In particular, medical staffs should improve the vigilance of smear-negative patients with suspicious symptoms to avoid the diagnosis delay.

Although DOTS have been fully covered, there are still delays in TB diagnosis which may be caused due to the long distance from home to the health center and the

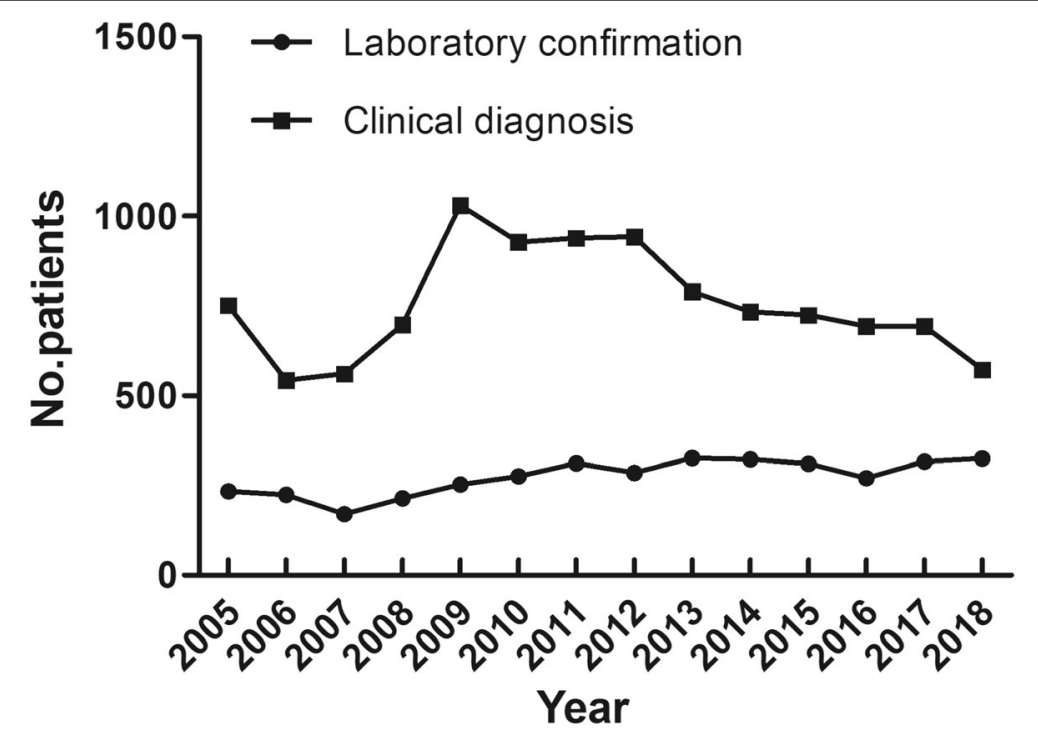

Fig. 2 The number of the laboratory confirmation and clinical diagnosis reported TB patients in the Haidian District, Beijing, 2005-2018 
Table 3 Diagnosis type for reported TB cases in Haidian District, 2005-2018

\begin{tabular}{|c|c|c|c|c|c|c|c|}
\hline \multirow[t]{2}{*}{ Year } & \multicolumn{3}{|l|}{ Bacteria positive } & \multirow{2}{*}{$\begin{array}{l}\text { Bacteria } \\
\text { negative } \\
\text { (cases) }\end{array}$} & \multirow{2}{*}{$\begin{array}{l}\text { Without } \\
\text { sputum } \\
\text { examination } \\
\text { (cases) }\end{array}$} & \multicolumn{2}{|l|}{ Total } \\
\hline & Swear-positive TB (cases) & Positive bacterial culture (cases) & Total (cases) & & & Positive rate (\%) & Rate of sputum (\%) \\
\hline 2005 & 179 & 6 & 185 & 440 & 361 & 18.76 & 63.39 \\
\hline 2006 & 165 & 27 & 192 & 391 & 184 & 25.03 & 76.01 \\
\hline 2007 & 169 & 1 & 170 & 379 & 183 & 23.22 & 75.00 \\
\hline 2008 & 196 & 18 & 214 & 504 & 194 & 23.46 & 78.73 \\
\hline 2009 & 272 & 10 & 282 & 716 & 285 & 21.98 & 77.79 \\
\hline 2010 & 260 & 22 & 282 & 675 & 247 & 23.42 & 79.49 \\
\hline 2011 & 314 & 29 & 343 & 612 & 296 & 27.42 & 76.34 \\
\hline 2012 & 281 & 25 & 306 & 624 & 298 & 24.92 & 75.73 \\
\hline 2013 & 299 & 34 & 333 & 548 & 237 & 29.79 & 78.80 \\
\hline 2014 & 288 & 35 & 323 & 533 & 201 & 30.56 & 80.98 \\
\hline 2015 & 283 & 27 & 310 & 501 & 225 & 29.92 & 78.28 \\
\hline 2016 & 250 & 19 & 269 & 487 & 209 & 27.88 & 78.34 \\
\hline 2017 & 280 & 37 & 317 & 514 & 180 & 31.36 & 82.20 \\
\hline 2018 & 251 & 72 & 323 & 420 & 156 & 35.93 & 82.65 \\
\hline Total & 3487 & 362 & 3849 & 7344 & 3256 & 26.64 & 77.47 \\
\hline
\end{tabular}

physical problem of many elderly people who have difficulty in walking. Housework and the unemployed, many of whom lived in rural areas and were older, also had this problem. Additionally, with the amount of housework and farm work, TB patients in rural villages felt it almost impossible to visit the long distant health centers. Even though TB diagnosis and treatment are free, they may not be able to afford the costs associated with other things in the diagnosis process such as accommodation, dinning. Although most of the patients knew TB disease, they were lacking in knowledge about the symptoms and few people were aware of its severity. Discrimination from others may also discourage them to have access to the healthcare services. All these factors contribute to the delays in diagnosis, so resulting in the high prevalence of TB among the elderly, housework and unemployed [16].

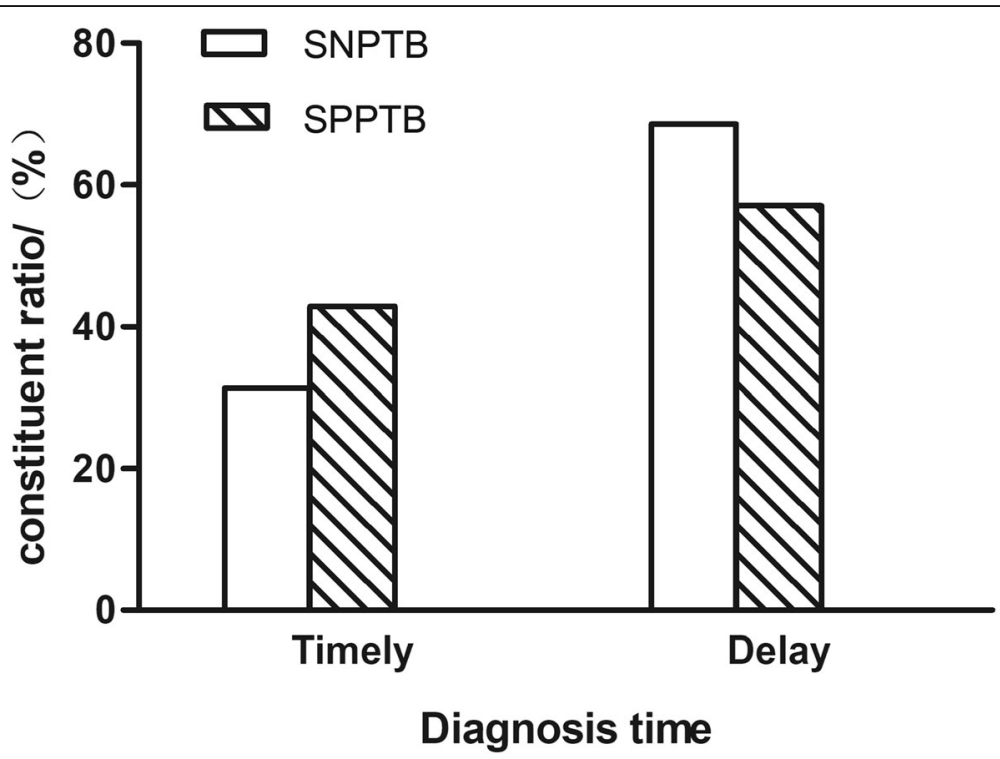

Fig. 3 The diagnosis time (in weeks) of TB. Differences in the constituent ratio between timely diagnosis and delayed diagnosis in SNPTB and SPPTB of reported TB cases in Haidian District, Beijing, 2005-2018 
In addition to causing the parenchyma of the lung, mycobacterium TB affects other areas other than the lung, leading to extrapulmonary tuberculosis (EPTB), most commonly pleurisy. EPTB is usually not an infectious disease. However, it can cause death if undiagnosed or untreated, especially in immunosuppressed individuals. EPTB patients were largely at 65 years or older, who had retired and was living in urban areas [17]. In our study, TB pleurisy has been reported every year. Notably, patients with HIV and diabetes were more likely to contract TB, but less likely to contract EPTB [18].

\section{Strengths and limitations}

In this study, we have carried out a detailed descriptive epidemiological study to provide data references for the TB control. However, there are still some limitations to our study. In the future, the qualitative methods should be applied to explore the reasons for delay in diagnosis, including studies on individual behaviour and characteristics embedded in social, cultural and health service. In addition, a large scale study to cover the whole of Beijing might be beneficial.

\section{Conclusions}

In conclusion, the overall incidence of TB in Beijing Haidian District dropped from 2005 to 2018, but there were still many new cases every year. National plans for TB control need to target populated regions, with special attention to elderly males without occupation who are at higher risk, and should strengthen publicity and education activities, especially in schools.

\section{Abbreviations}

TB: Tuberculosis; DOTS: Directly Observed Treatment, Short-course; AFB: Acidfast Bacilli; PTB: Pulmonary Tuberculosis; SPPTB: Smear-positive Pulmonary Tuberculosis; SNPTB: Smear-negetive Pulmonary Tuberculosis; EPTB: Extrapulmonary Tuberculosis; SARS: Severe Acute Respiratory Syndrome

\section{Acknowledgements}

Not applicable.

\section{Authors' contributions}

FW, $C L$ and $Y W$ interpreted the data and wrote the manuscript. GZ and $Y L$ collected and collated data. SY, XP and JY revised the work. The study on which this paper was conceived and designed by ZW and WZ. All authors have commented on drafts of the paper and approved this submitted version.

\section{Funding}

This work was funded by National Natural Science Foundation of China (81473014); Top Young Talents of Guangdong Hundreds of Millions of Projects (87316004); Jinan University High-level University Construction Public Health and Preventive Medicine Fund (JNUPHPM2016003); Outstanding Young Talent of Double Hundred Talents Plan in Jinan University; Open Fund of State Key Laboratory of Respiratory Diseases (SKLRD-OP-201810). The funding body had no role in the design of the study and collection or in the analysis and interpretation of the data or in writing the manuscript.

\section{Availability of data and materials}

Data of the study was not publicly available, the datasets used and analyzed during the current study are available from the corresponding author upon reasonable request. Restrictions apply to the availability of these data, which were used under license for the current study, and so are not publicly available. Data are however available from the authors upon reasonable request and with the permission of Four Seasons Hospital.

\section{Ethics approval and consent to participate}

According to National Health Commission of the People's Republic of China [19], data involved in this study did not include any data of patients' personal information, including name, identity information, exact address, telephone number, etc. This study mainly focused on aggregating the available data, so consent to participate and ethics approval are unnecessary.

\section{Consent for publication}

Not applicable.

\section{Competing interests}

The authors declare that they have no competing interests.

Received: 8 January 2020 Accepted: 24 April 2020

Published online: 01 June 2020

\section{References}

1. WHO. Global tuberculosis report. Geneva: World Health Organization. 2018:2018.

2. Hou WL, Song FJ, Zhang NX, Dong XX, Cao SY, Yin XX, Liu JN, Lu ZX. Implementation and community involvement in DOTS strategy: a systematic review of studies in China. The international journal of tuberculosis and lung disease. 2012;16:1433-40.

3. Wang L, Liu J, Chin DP. Progress in tuberculosis control and the evolving public-health system in China. Lancet. 2007;369:691-6.

4. Lixia W, Shiming C, Mingting C, Yanlin Z, Hui Z, Shiwen J, Guangxue H, Qing L, Xin D, Wei C, Xiaoqiu L, Yunzhou R, Shengfen W, Yinyin X, Lan Y, Qun L, Xue L. The fifth national tuberculosis epidemilolgical survey in 2010. Chin J Antituberc. 2012;34:485-508.

5. Wei X, Yuan L, Ruiying L, Yunfang W. Epidemiological analysis of pulmory tuberculosis in Chaoyang District of Beijing from 2013-2017. Occup Health. 2019;35:1208-11.

6. Wei L, Yang $Z$ and Jianjun $L$. The Progress and achievements of tuberculosis control in China since 1949. Chin J Dis Control Prev. 2019: 754-7+62.

7. Rajagopalan S. Tuberculosis in older adults. Clin Geriatr Med. 2016;32: 479-91.

8. Ziv E, Daley $\mathrm{CL}$, Blower S. Potential public health impact of new tuberculosis vaccines. Emerg Infect Dis. 2004;10:1529-35.

9. Zhao Y, Li M, Yuan S. Analysis of transmission and control of tuberculosis in mainland China, 2005-2016, based on the age-structure mathematical model. Int J Environ Res Public Health. 2017;14.

10. Pan D, Lan R, Graviss EA, Lin D, Liang D, McNeil E, Lin M, Chongsuvivatwong V. Adolescent tuberculosis associated with tuberculosis exposure in classrooms and dorm rooms in Guangxi, China. IJID. 2019;78:8-14.

11. Demin C, Zhiguo Z, Zhen Y, Shubo M, Zhaogang S, Huijuan D, Baoli Z, Fei Z. The association between tuberculin skin test result and active tuberculosis risk of college students in Beijing, China: a retrospective cohort study. BMC Infect Dis. 2019;19.

12. Huang Y, Zhong J, Wu Q, Liu Z, Pan A, Zhu L, Wang X. Investigation of a large school-based outbreak of tuberculosis infection in eastern China. Pediatr Pol. 2016; 91:541-6.

13. Gegia M, Magee MJ, Kempker RR, Kalandadze I, Chakhaia T, Golub JE, Blumberg HM. Tobacco smoking and tuberculosis treatment outcomes: a prospective cohort study in Georgia. Bull World Health Organ. 2015;93:390-9.

14. Ospina JE, Orcau A, Millet JP, Ros M, Gil S, Cayla JA. Epidemiology of tuberculosis in immigrants in a large City with large-scale immigration (1991-2013). PLoS One. 2016;11:e0164736.

15. Yang S, Wu J, Ding C, Cui Y, Zhou Y, Li Y, Deng M, Wang C, Xu K, Ren J, Ruan B, Li L. Epidemiological features of and changes in incidence of infectious diseases in China in the first decade after the SARS outbreak: an observational trend study. Lancet Infect Dis. 2017;17:716-25.

16. Marahatta SB, Yadav RK, Giri D, Lama S, Rijal KR, Mishra SR, Shrestha A, Bhattrai PR, Mahato RK, Adhikari B. Barriers in the access, diagnosis and treatment completion for tuberculosis patients in central and western Nepal: a qualitative study among patients, community members and health care workers. PLoS One. 2020;15:e0227293. 
17. Wang $X$, Yang $Z$, Fu $Y$, Zhang $G$, Wang $X$, Zhang $Y$, Wang $X$. Insight to the epidemiology and risk factors of Extrapulmonary tuberculosis in Tianjin, China during 2006-2011. PLoS One. 2014;9:e112213.

18. Pang Y, An J, Shu W, Huo F, Chu N, Gao M, Qin S, Huang H, Chen X, Xu S. Epidemiology of Extrapulmonary tuberculosis among inpatients, China, 2008-2017. Emerg Infect Dis. 2019;25:457-64.

19. National Health Commission of the People's Republic of China. Methods of Ethical Review of Biomedical Research Involving Human Beings. 2016-10-12.

\section{Publisher's Note}

Springer Nature remains neutral with regard to jurisdictional claims in published maps and institutional affiliations.

Ready to submit your research? Choose BMC and benefit from:

- fast, convenient online submission

- thorough peer review by experienced researchers in your field

- rapid publication on acceptance

- support for research data, including large and complex data types

- gold Open Access which fosters wider collaboration and increased citations

- maximum visibility for your research: over $100 \mathrm{M}$ website views per year

At $\mathrm{BMC}$, research is always in progress.

Learn more biomedcentral.com/submissions 